\title{
Psicoanálisis y Género: debates actuales y nuevas construcciones subjetivas
}

\author{
Psychoanalysis and Gender: current debates and new subjective constructions
}

Irene Meler

Foro de Psicoanálisis y Género de la Asociación de Psicólogos de Buenos Aires -

Universidad Argentina John F. Kennedy - Universidad de Ciencias Empresariales y Sociales, Argentina meleirene6@gmail.com

\begin{abstract}
Resumen:
El presente artículo se propone examinar críticamente la intersección entre los estudios interdisciplinarios de género y las teorías psicoanalíticas sobre el psiquismo y la subjetividad. Se realiza un recorrido por los diferentes modos en que la condición femenina ha sido considerada conceptualmente en el marco de diversas miradas disciplinares que hoy, retrospectivamente, integran una genealogía de los feminismos que acuden a la categoría de género, en diálogo con el psicoanálisis. Luego de explorar el vínculo ambivalente y conflictivo entre miradas de género y perspectivas psicoanalíticas, se ofrece un examen de los nexos entre las categorías de cuerpo, psiquismo y condición social de los sujetos.

Palabras Clave: Psicoanálisis, Género, Subjetividad, Campo social.
\end{abstract}

\section{Abstract:}

This paper give an account of the intersection between interdisciplinary gender studies and psychoanalytic theories about psyche and subjectivity. A exposition of different aspects in which female condition has been considered conceptually within the framework of various disciplinary perspectives that today, retrospectively, integrate a genealogy of feminisms that dialogue with the gender category and with psychoanalysis. After exploring the ambivalent and conflicting link between gender and psychoanalytic perspectives, an examination of the bonds between body, psyche and social condition of the subjects is offered.

KEYWORDS: Psychoanalysis, Gender, Subjectivity, Social field.

\section{INTRODUCCIÓN}

La dominación social masculina, con infinitos matices y variantes, ha coincidido con la historia de la civilización. Construidas al interior de ese dispositivo, las mujeres han manifestado disconformidad con su condición social y con su estatuto simbólico, aunque su rebelión ha conocido tanto períodos explosivos como prolongadas latencias. Hoy se ha iniciado una etapa que podemos denominar como "el siglo de las mujeres", debido a los profundos cambios que se están produciendo en el sistema de géneros, que avanza en el sentido de la paridad.

Las categorías de feminidad y masculinidad, propias del binarismo moderno, han entrado en ignición y son objeto de cuestionamiento. Las identidades sexuadas, hasta hace poco concebidas como referencias firmes, se diluyen, y a lo sumo se discute acerca de si se mezclarán sobre el modelo del melting pot, al estilo del puré, o del salad bowl, o sea, en fragmentos que conserven alguna forma distintiva (Fausto Sterling, 2006).

El campo social está habitado por sujetos disidentes respecto de las categorías tradicionales, pero esas normativas continúan organizando la vida cotidiana y las relaciones amorosas de las grandes mayorías poblacionales. Cuando intentamos, de acuerdo con alguna aspiración taxonómica, tipificar los estilos subjetivos ampliando la categoría binaria M/F que ha constituido "la diferencia sexual", los sujetos que se 
declaran gender fluid, echan por tierra ese afán orientador que, como toda clasificación, no está exento de motivaciones vinculadas con el poder.

Si historiamos de modo somero el campo de estudios donde desarrollamos nuestra tarea, veremos que la condición femenina fue en un comienzo el objeto de los Estudios de la Mujer. Sujeto tan abstracto como mítico, La Mujer, fue sin embargo necesaria como ficción reguladora, para lograr la institución de una nueva mirada que rescatara la existencia femenina del cono de sombras en que transcurría, no sólo en la experiencia cotidiana, sino también en los discursos de saber y en las prácticas de poder.

Gayle Rubin (1986) acuñó el concepto antropológico de sistema sexo género, para referirse a un dispositivo de regulación social que, de modo implícito, establecía las uniones sexuales permitidas y de ese modo daba lugar al parentesco, pero también a las subjetividades feminizadas y masculinizadas tal como aún hoy las conocemos. A partir de esta modelización, se crearon las bases para comprender la artificiosidad implícita en el recorte epistémico de la condición femenina, ya que en el interior de ese sistema, feminidad y masculinidad funcionan de modo sincronizado, tal como lo expresó Jessica Benjamin (1997).

Había que estudiar entonces a los varones, a quienes se había desplazado de su representación espuria de la totalidad de la especie humana, para caracterizarlos en su especificidad, y de ese modo, abordar las fuentes de su malestar cultural. Así como los Estudios de la Mujer fueron llevados a cabo por mujeres que constituimos una cierta vanguardia en el proceso de modernización de las relaciones de género, los Estudios sobre Varones, o Men's Studies, que ya nacieron plurales, han sido expresión de la incomodidad que muchos varones experimentan ante las elevadas exigencias que les impone el ideal de la masculinidad hegemónica (Connell, 1995). Algunas mujeres hemos constituido una excepción respecto de la tendencia a considerar que los estudios sobre masculinidad correspondían a los investigadores varones: en Francia, Elisabeth Badinter (1993), en Argentina, Mabel Burin e Irene Meler (2000), y Mara Viveros Vigoya (2002) en Colombia, entre otras, asumimos el desafío de analizar la condición masculina, que en nuestro caso fue encarada desde una perspectiva que articulaba el feminismo con el psicoanálisis.

En cuanto a los Estudios de la Mujer, la comprensión acerca de la heterogeneidad existente al interior del colectivo femenino hizo estallar rápidamente la abstracción ilusoria que lo unificaba, para habilitar el cambio hacia la denominación de Estudios de las Mujeres. La diversidad existente dentro de estas nuevas categorías, sólo pudo ser reconocida con posterioridad a un momento inicial en que fue necesario establecerlas, rescatándolas de la naturalización a la que estuvieron sometidas en los discursos del saber. Ya no se trataba del reconocimiento obvio acerca del hecho de que somos una especie de reproducción sexual, sino de la comprensión de la índole social e histórica de esas denominaciones, y del modo en que habían dado lugar a la institución de relaciones jerárquicas de poder.

Hubiera sido moralmente más reconfortante trazar una línea divisoria donde de un lado se ubicaran las víctimas inocentes de la opresión y, del otro, los opresores. Pero ese confort maniqueo nos fue negado, y hemos debido reconocer no sólo las asimetrías de poder existentes entre las mujeres, sino las relaciones de opresión y subordinación a las que esas jerarquías han dado origen. Fueron las otras, las mujeres pertenecientes a etnias derrotadas y subalternizadas, las académicas que accedieron al conocimiento desde orígenes familiares de escasos recursos, las negras, las lesbianas, en fin, los sujetos femeninos que intersecaban en su experiencia los más variados órdenes de subalternización, quienes tomaron la palabra para crear sentidos acerca del modo en que sus particulares condiciones de vida condicionaron su malestar, y, en consecuencia, estimularon su pensamiento (Hooks et al., 2004). En Argentina, el rápido ascenso social al que accedieron algunas generaciones, hizo coincidir para muchas de nosotras a la otra que hubiéramos podido ser, con la intelectual de clase media que recurría a sus ventajas de clase para luchar contra sus desventajas de género.

Y después llegaron los raros, los sujetos que no encajaban en las categorías dicotómicas del binario sexo/ género, aquellos cuyo sexo no se alineaba del modo mayoritariamente ordenado con su sexualidad, su deseo, y tampoco con su sentimiento de sí, con su identidad. Cuando los gays, las lesbianas, los transgénero y los estados intersexuales tomaron la palabra, constituyendo el campo de los Queer Studies, fue posible captar 
la extensión y la profundidad con que el sistema de géneros rige nuestras vidas. La percepción tradicional acerca del género subjetivo, que lo consideró como la expresión cultural y psíquica del sexo biológico, se vio conmocionada por la exposición de experiencias que han puesto de manifiesto el alcance de la construcción colectiva de las diferencias sexuales. Considero que un eje importante del debate actual en el interior de estos campos de estudio, se refiere a la tensión existente entre el reconocimiento de los aspectos estructurantes del sistema de géneros, versus la atribución de un carácter opresivo que promueve su desaparición como dispositivo regulatorio de los intercambios sociales, eróticos e intersubjetivos.

¿Cómo y por qué se ha producido el diálogo entre los estudios sociales, históricos, biológicos y filosóficos, con el psicoanálisis, una teoría sobre el psiquismo surgida a comienzos del siglo XX?

Los estudios inspirados en el feminismo, animados por la aspiración hacia la paridad entre los géneros, han presentado, por un lado, una dimensión descriptiva que denunció los efectos adversos de los ordenamientos tradicionales y, por el otro, un aspecto utópico, encaminado hacia la construcción de subjetividades alternativas. Las mujeres innovadoras hemos sido, a la vez, objetos y sujetos de esta tendencia histórica. Las transformaciones acaecidas en el modo de producción capitalista, que transitó desde una fase productivista hacia la actual sociedad de consumo, requirieron de hogares con dos proveedores. Las nuevas prácticas educativas y laborales de las mujeres, desempeñadas en un contexto donde la crianza y la domesticidad han sido privatizadas, promovieron el cultivo de modalidades alternativas de subjetividad femenina. Fue necesario comprender los modos de ser que eran divergentes con respecto de los estereotipos modernos tradicionales, y ganar legitimidad para los mismos, resistiendo a su patologización. Con ese propósito, muchas teóricas feministas comenzaron a interesarse por las teorías psicoanalíticas, que también se utilizaron como referencia para el propósito de promover la construcción de nuevas subjetividades, que acompañaran y potenciaran la transformación de las relaciones de género. Resultó evidente que la revolución de las prácticas sociales y los valores e ideales vigentes acerca de la feminidad y la masculinidad, no sería posible sin una mutación de las subjetividades. El psicoanálisis es aún hoy, pese a sus innegables sesgos androcéntricos y sexistas, el cuerpo teórico que mayor riqueza y profundidad ofrece para los análisis sobre el psiquismo y los vínculos intersubjetivos. Es por eso que se inauguró un diálogo complejo, muchas veces disonante y conflictivo, pero siempre fecundo, entre los estudios feministas y los estudios psicoanalíticos, y esas discusiones continúan hasta hoy, sin perder vigencia.

Este intercambio, y los nexos significativos que derivan del mismo, es muy complejo, porque ambos campos de estudios presentan desarrollos internacionales y, a la vez, están habitados por varias corrientes teóricas que han surgido en función de la diversidad de los contextos culturales, y también bajo el influjo de distintas concepciones filosóficas y proyectos políticos. De modo que habitamos una Babel donde se contraponen, dialogan y muchas veces luchan, modelos o ideales alternativos sobre los géneros, las sexualidades, las familias y las formas de trabajo. Diversas/os autores proponen modelos acerca de interrogantes cruciales: ¿quiénes somos?, ¿somos algo, o simplemente estamos?, ¿existen algunos invariantes estructurales del psiquismo humano?, ¿cuáles son sus alcances?, ¿cómo podemos convivir?, ¿cómo amar?, ¿de qué modo superar la escasez y mejorar las condiciones de vida para todes?, ¿cómo criar?, ¿qué podemos hacer para evitar los riesgos de destrucción?

Como puede advertirse, estas son cuestiones que nos implican profundamente y ponen en juego nuestra existencia. El intercambio de los estudios interdisciplinarios de género con las teorías psicoanalíticas sobre el psiquismo y la subjetividad, aporta una contribución significativa para un avance que nunca llegará a un destino final, pero que puede obtener logros provisorios.

\section{LOS MAPAS DEL TERRITORIO}

Son muchas las autoras que han trabajado en este nexo existente entre el psicoanálisis y los estudios de género, y se ha instalado una tradición que condujo a varias entre ellas a trazar mapas del campo de 
estudios con el fin de establecer tendencias que fueron variando a lo largo de los años, y destacar coincidencias o divergencias entre distintas líneas teóricas. En Estados Unidos, Nancy Chodorow, psicoanalista feminista, dedicó un trabajo a esa cartografía, publicado en su libro Feminism and Psychoanalytic Theory (1989). Jane Flax (1995), una filósofa, epistemóloga, cientista política y terapeuta feminista, también residente en Estados Unidos y perteneciente al psicoanálisis anglosajón intersubjetivo, organizó su obra dedicada al diálogo entre psicoanálisis, feminismo y postmodernismo, sobre la base de exponer y, a la vez, hacer objeto de un análisis crítico, a los desarrollos psicoanalíticos freudianos, winnicottianos y lacanianos, a las diversas corrientes del pensamiento feminista y a los filósofos postmodernos. El diálogo que promovió entre estos cuerpos teóricos ha sido muy productivo para iluminar las omisiones y sesgos que, de modo inevitable, presenta cada discurso. Donna Haraway (1991), una bióloga y filósofa norteamericana que se ha interesado en la posible relación entre el discurso psicoanalítico y las corrientes teóricas feministas, también mapeó este territorio en su artículo sobre el sistema sexo/género, destinado a un diccionario marxista de habla germana. Desde Europa, Rosi Braidotti (2000), quien lidera una corriente feminista diferencialista que se propone superar el esencialismo y la universalización que caracterizaron el pensamiento de Luce Irigaray (1974), ha aportado su propio mapa. Silvia Tubert, una psicoanalista argentina que desarrolló su labor en Madrid, realizó una reseña exhaustiva de los desarrollos internacionales de este campo de estudios, en el prólogo del libro de Jane Flax (1995), a quien hizo conocer entre los lectores de habla hispana. Más allá del reconocimiento debido a las pensadoras que aportaron perspectivas originales y productivas, me interesa destacar algunas cuestiones que me resultaron de interés.

Chodorow (1989) establece una diferencia entre los psicoanalistas profesionales, que sólo recientemente se han interesado en los debates acerca de las mujeres y la feminidad, y otras investigadoras/es que estudian la subjetividad desde perspectivas informadas por el feminismo. En Argentina se observa una tendencia semejante: los analistas de las asociaciones integradas en la Asociación Psicoanalítica Internacional (IPA) han acatado hasta hace poco el pacto implícito de silencio acerca de los debates sobre la sexualidad femenina y la feminidad. Ese tema generó tanto disenso, que amenazó con fracturar un campo de estudios que luchaba por ganar reconocimiento en las comunidades científicas, y por ese motivo, quedó en suspenso, congelando los debates hasta ocasiones más favorables. Mientras tanto, prevaleció el discurso freudiano, que se encuadra en el paradigma grecolatino de la mujer considerada como un varón menor o un castrado. El sujeto modélico del discurso freudiano es masculino, y la feminidad constituye un enigma para esta perspectiva androcéntrica. He expuesto en una publicación anterior (Meler, 2013) mi análisis crítico acerca de algunos ejes del edificio freudiano sobre la psicología de las mujeres. La envidia fálica ha sufrido una hipertrofia teórica que la transformó en el motivo organizador de la vida psíquica de las mujeres, desestimando las observaciones clínicas que indican que esta emoción se encuentra también entre los varones, con la diferencia de que en ellos los deseos de identificarse con la feminidad suelen ser rigurosamente reprimidos, por causa de la devaluación cultural de la condición femenina.

También he objetado la atribución de pasividad que Freud realizó respecto de las mujeres, utilizando un razonamiento circular, que partió de las observaciones psicosociales que, efectivamente, mostraban un predominio de actitudes pasivas ante la existencia, en mujeres cuyo estatuto social las ubicaba al interior de la familia, acotando sus roles a la domesticidad y a la maternidad. El creador del psicoanálisis explicó estos observables clínicos característicos de su época, mediante una referencia a la anatomía receptiva del genital femenino, a la que transformó, mediante una operación ideológica, en una disposición pasiva del psiquismo. De acuerdo con una versión algo ruda del influjo psíquico de la psico-sexualidad humana, consideró que esta pasividad atribuida a la vagina, determina la condición social y subjetiva de las mujeres. El carácter de los sujetos, según ese modelo teórico, se calcaba sobre la anatomía y sobre la función de los genitales en el coito reproductivo. El devenir histórico no ha confirmado ese supuesto reduccionista, lo que me exime de mayores comentarios. 
Otra "imputación" freudiana contra las mujeres consistió en considerarlas como más narcisistas en comparación con los varones, a quienes atribuyó una mayor capacidad de amar a su objeto de deseo, sobrevalorado en el contexto del enamoramiento. Consideró que las mujeres preferían ser amadas en lugar de amar de modo activo, y que su amor maternal, difícil de negar aún para una perspectiva misógina, se explicaba por el hecho de que los hijos habían formado parte del propio cuerpo, por lo cual, el amor materno constituía una variante del egoísmo. He expuesto mi opinión acerca de que Freud posiblemente confundió con una genuina indiferencia y autosuficiencia, las inhibiciones que la cultura de su tiempo impuso sobre la expresión del deseo erótico femenino. En realidad, no asistió a una carencia de interés erótico por parte de las mujeres, sino que confundió el sentido de su aparente indiferencia, que fue fingida para encubrir el deseo y protegerse de un rechazo considerado como humillante.

En cuanto al masoquismo que atribuyó a las mujeres y que describió como una preferencia erótica por ser atadas, humilladas, poseídas sexualmente o parir (Freud, 1980 [1924]), expuse mi pensamiento acerca de que en ese aspecto Freud confundió las fantasías puberales de los varones sexualmente inmaduros, acerca de cómo podrían gozar si fueran mujeres, con los deseos típicamente femeninos. Esa imaginería erótica teñida de lucha, sometimiento, humillación y gusto por la suciedad, es típicamente masculina, y fue atribuida a las mujeres mediante una proyección del imaginario varonil masoquista. De hecho, quienes pagan a mujeres prostituidas para ser sometidos a malos tratos, son en su enorme mayoría varones. Tal vez eso suceda, como lo consideró irónicamente Louise Kaplan (1994), porque las mujeres conseguimos ser maltratadas, de modo gratuito.

Los desarrollos teóricos freudianos que constituyeron una apoteosis del sexismo, se refirieron a las características de la formación Super Yo en las mujeres. El creador del psicoanálisis teorizó acerca de la constitución evolutiva de funciones psíquicas que operan como una conciencia reflexiva, que sirve a la finalidad de inhibir los actos impulsivos, cuando los considera lesivos para otros o para sí. Relacionó su surgimiento con la renuncia del varón a sus aspiraciones edípicas de poseer a la madre de modo exclusivo, desplazando al padre y ocupando su lugar. Describió la actividad autoerótica de los niños pequeños, y los efectos de la pedagogía victoriana, que cuando los adultos percibían la estimulación masturbatoria de los genitales, indicaba amenazar al niño con cortar su pene, o en su lugar, la mano transgresora. Freud observó que en un principio el niño descreía de tales amenazas, pero que ante la visión de los genitales femeninos, percibidos como efecto de una castración de los genitales masculinos, daba crédito al amedrentamiento que había padecido, y renunciaba, tanto al autoerotismo como a las fantasías amorosas que lo acompañaban, dirigidas hacia la madre como objeto de deseo. En el caso de las niñas, al ser sus genitales internos, eran significados como efecto de una castración ya realizada. (Resulta notable la ceguera de este razonamiento ante la asunción de la anatomía masculina como modelo o ideal, incluso por parte de las mujeres). Perdido por perdido, las niñas no sepultaban su Complejo de Edipo de modo tan categórico como lo que ocurría en los varones y esto redundaba en una mayor laxitud moral, cierta imperfección de la formación Super Yo. Las mujeres freudianas eran renuentes a someterse a las leyes generales que rigen la existencia (Freud no cuestionó esa legalidad) y buscaban siempre algunas excepciones y dispensas respecto de su cumplimiento. Esta concesión femenina ante los propios deseos, no permitía el ahorro energético característico del psiquismo de los varones. Ellos destinaban la energía libidinal no empleada en la satisfacción directa de sus deseos, a funciones más elevadas. Mediante un recuso defensivo que Freud denominó como "sublimación", trocaban la meta proscripta de la pulsión por una finalidad aceptada y valorizada por la cultura vigente. Así, el niño cruel podía ser cirujano o soldado, y el niño sucio transformarse en escultor o pintor. "Las criaturas sin pene" pagaban su reticencia a someterse a las regulaciones morales mediante una merma de su creatividad, que explicaba, según Freud, su escasa contribución a la cultura. Una excepción se encontraba en la invención de la cestería, creada, según pensó, a partir de entretejer el vello púbico para disimular "la defectuosidad de los genitales" (Freud, 1980 [1933]).

Es comprensible que los psicoanalistas que integran las asociaciones oficiales no se sientan propensos a recordar este capítulo del pensamiento freudiano, y prefieran encarar otros desarrollos. A esto se agrega que la 
rápida transformación de la condición femenina y el reconocimiento del carácter incompatible del dominio masculino con la democratización social occidental, ha colocado a los psicoanalistas ante subjetividades que interpelan sus conocimientos convalidados y promueven un necesario trabajo de revisión teórica. Es así como han comenzado, con retraso respecto de los desarrollos feministas, a interesarse en la psicología de las mujeres y con ese propósito han creado al interior de sus instituciones, el Comité de Mujeres y Psicoanálisis (COWAP), una comisión destinada a tal efecto.

Chodorow (1989) puntualiza que estos expertos suelen manejarse al interior de un paradigma positivista, consideran que las observaciones clínicas bastan para validar sus teorías y conciben su práctica como un ejercicio profesional donde se desempeñan como terapeutas cuya función es aliviar el sufrimiento de quienes los consultan. En estos abordajes, la autora considera que las consideraciones políticas se encuentran ausentes.

Ante esta caracterización surge una observación obligada: las consideraciones políticas no aparecen en el contenido manifiesto de los estudios psicoanalíticos oficiales, pero su presencia es tanto más eficaz por el hecho de ser desmentida. Las representaciones predominantes en los sectores sociales medios urbanos inciden con frecuencia en el pensamiento psicoanalítico instituido, promoviendo lecturas e interpretaciones cuyo carácter ideológico transita de modo inadvertido bajo una apariencia de cientificidad.

Siguiendo con el mapa trazado por Chodorow, vemos que establece otra categoría, constituida por las psicoanalistas feministas, que enfatizan el Freud de "La moral sexual cultural y la nerviosidad moderna", consideran al género y a la sexualidad como aspectos de la subjetividad que no son innatos sino que han sido construidos, y se interesan por las formas en que se construye el género, más allá de las prescripciones normalizadoras que describen estadios del desarrollo psicosexual semejantes para todos. Algunas de estas investigadoras realizan contribuciones clínicas sobre estos supuestos, y unas pocas plantean alternativas para modificar la psicología de las mujeres que está en vigencia en la actualidad.

La alusión de Chodorow al artículo freudiano, merece una explicación. En 1908, una contribución freudiana pionera, titulada La moral sexual cultural y la nerviosidad moderna (Freud, 1980 [1908]) nos abría un camino que hoy conviene retomar. En contraposición a Moebius, autor de un best seller de la época llamado La imbecilidad fisiológica de las mujeres, Freud buscó una explicación alternativa para un observable que compartía con ese autor: la mayor parte de las mujeres que él conocía, no alcanzaban un desarrollo intelectual comparable al promedio de los varones. Pero no era la fisiología la clave adecuada para explicar esa situación. Un filósofo alemán, Christian Von Ehrenfels, había descrito la existencia de una doble moral sexual en la cultura: las mujeres eran objeto de regulaciones mucho más severas en materia de sexualidad que las que se aplicaban para los hombres. Constreñidas por la prohibición de saber acerca de los dos interrogantes que movilizan la pulsión epistemofílica infantil: el origen de los niños y la diferencia sexual, las mujeres inhibían la totalidad de su deseo de saber, y esto explicaba, según pensó Freud, su menor desarrollo intelectual. Vemos aquí un argumento que enfatiza las determinaciones sociales, culturales y políticas en la construcción de la subjetividad sexuada. Freud agregó otra observación que fue precursora del estudio de las tendencias epidemiológicas diferenciales según género: en una misma familia era usual que convivieran una hermana refinada, reprimida y neurótica, con un hermano saludable pero perverso. Aparece aquí una consideración de la represión como la defensa más frecuente entre las mujeres, con la consiguiente formación de síntomas neuróticos, mientras que la pulsión lograba abrirse paso hacia su satisfacción directa, abusiva y no refinada en el caso de los varones, cuyo exceso de poder los hacía proclives a generar padecimientos en los demás, más que a sufrir ellos mismos. Muchos males se derivaban de este arreglo social inequitativo: los niños eran depositarios del anhelo erótico insatisfecho de sus madres, lo que los predisponía a la neurosis, y la unión conyugal, el bien que se había pretendido preservar mediante la inhibición sexual de las mujeres, se veía corroída por el dificultoso encuentro entre una esposa ignorante y temerosa, y un marido iniciado en la práctica sexual con mujeres degradadas.

Lamentablemente este camino que prometió articular el estudio del psiquismo con el contexto social y con las relaciones de poder que lo atraviesan, no fue continuado, y pocos años después, en 1918, otro Freud 
(1980 [1918]), olvidando sus posturas anteriores, consideraba al reclamo cultural de la virginidad femenina como un recurso lícito para sostener la monogamia. A partir de allí la radicalidad de su discurso dio lugar a una expresión de las tendencias conservadoras de la época, en contraposición a otras corrientes progresistas de pensamiento que Freud conoció muy bien, ya que, para dar un ejemplo, tradujo personalmente la obra donde John Stuart Mill (2010 [1869]) cuestionó el estatuto social de las mujeres.

Si retornamos al mapa diseñado por Chodorow, veremos que establece otra categoría dentro de las investigaciones sobre las mujeres y la feminidad. Quienes son denominadas por la autora como las feministas psicoanalíticas, se caracterizan por una preocupación teórica, filosófica y epistemológica, que trabaja de modo intertextual y se desentiende de la clínica. Mientras que las psicoanalistas feministas se interesan por los criterios de verdad, el otro grupo adopta una versión interpretativa donde lo que importa es la coherencia narrativa.

Nos encontramos de modo claro ante un debate interno, que se relaciona, por un lado, con el hecho de que aquellas que agrupa bajo la denominación de psicoanalistas feministas, donde se incluye, desarrollan una práctica clínica, mientras que las feministas psicoanalíticas son las filósofas y literatas de los departamentos universitarios de esas especialidades, que desarrollan investigaciones teóricas y no se vinculan, a través de la asistencia del malestar, con las personas reales de su entorno. La obra de Judith Butler, entre otras, está incluida de modo implícito en esta categoría. No me parece aventurado agregar que la orientación sexual de las autoras es un factor que debemos incluir para comprender sus desarrollos teóricos y sus divergencias, ya que una epistemología inspirada en el feminismo incluye de modo significativo los efectos de la posición del sujeto cognoscente en el campo social en la producción de conocimientos. Las indagaciones de Chodorow han comenzado con el análisis del ejercicio de la maternidad (1984) y se enfocaron en la reproducción social de esa práctica, considerada por las feministas de los años '70 como un eje fundamental de la subordinación social femenina. El estudio de la construcción subjetiva de las mujeres al interior de las familias nucleares urbanas de clases medias, fue emprendido por la autora con el propósito de detectar el modo en que se reproducía el deseo de ejercer la maternidad entre las mujeres, mientras que se inhibían en los varones los deseos de prodigar cuidados a los niños. Esta indagación se consideró de importancia estratégica para el logro de una aspiración social: la incorporación de las mujeres al mercado de trabajo remunerado, considerada como la clave para el logro de su paridad ciudadana.

Jessica Benjamin (1996), por su parte, inició su tarea investigando sobre las relaciones de dominación erótica. Para comprender las tendencias femeninas hacia el sometimiento con respecto de los varones, realizó un estudio psicoanalítico del desarrollo temprano en el contexto de las familias nucleares, con la aspiración de encontrar las claves subjetivas de las relaciones de dependencia emocional que contribuyen a la subordinación social de las mujeres.

Es fácil observar que estos temas de interés son propios de mujeres de clases medias, profesionales y heterosexuales, que estaban llevando a cabo una lucha política y a la vez, un proceso de deconstrucción personal, con el propósito de lograr transformaciones subjetivas que habilitaran una transformación cultural de las relaciones de género. Corresponde reconocer que esa aspiración está más cerca de concretarse en nuestros días.

En cambio, las preocupaciones de las filósofas que inauguraron los estudios queer, se relacionan con la defensa de los derechos civiles de la comunidad GLTTBIQ+1, una meta que requiere un profundo cuestionamiento del sistema de géneros vigente. Su aspiración política consiste en una transformación del orden simbólico que habilite el reconocimiento social hacia los sujetos cuyos avatares biográficos han condicionado que su sexo, género y deseo no se alineen del modo que predomina desde una perspectiva estadística. La influencia cultural de estos estudios es enorme, y han contribuido a la democratización social, aflojando el control policial de las identidades sexuadas y los deseos eróticos, y promoviendo el respeto por la diversidad. 
También es posible registrar algunas inexactitudes, producto del afán por luchar contra la patologización de la homosexualidad, que se pueden achacar al teoricismo y a la escasa o nula conexión con la experiencia clínica por parte de estas autoras, que no son psicoanalistas sino filósofas. Una cuestión ilustrativa, se refiere al concepto de "melancolía de género" creado por Judith Butler (2007), quien nos recuerda que el Complejo de Edipo es completo, o sea que en él coexisten la corriente psíquica heterosexual, que dirige el deseo amoroso hacia el progenitor del sexo opuesto, con la corriente homosexual, que vehiculiza el amor hacia el progenitor del mismo sexo. Partiendo de esa consideración freudiana, expresa que al resolverse el conflicto edípico del modo socialmente convalidado, las identificaciones con el progenitor del mismo sexo, que forman las bases de la feminidad en las mujeres y de la masculinidad en los varones, constituyen el residuo del amor objetal al que el sujeto ha debido renunciar para construirse de acuerdo con las prescripciones instituidas. De modo que las identidades normalizadas encerrarían en sí mismas el deseo resignado de cruzar géneros. Esta argumentación ingeniosa, fue concebida para refutar el nexo que se suele realizar en el campo del psicoanálisis entre la melancolía y la homosexualidad, lo que contribuye a una patologización ante la cual los sujetos queer están, de modo comprensible, muy alertas. Butler universalizó el concepto de melancolía, extendiéndolo a la subjetivación heterosexual. Considero que la asociación entre homosexualidad y melancolía puede ser matizada, refiriendo a los efectos de la discriminación la asociación clínicamente observable -aunque está lejos de ser universal- entre elección homosexual de objeto y estructuras de personalidad depresivas o melancólicas. La experiencia reiterada a lo largo de los años, de encubrir la propia forma de ser por temor a la penalización de la policía de Género (Kimmel, 1994), favorece la erosión de la estima de sí de quienes han atravesado por esa modalidad lesiva de control social. En cambio, no acuerdo con concebir que el amor temprano de los niños hacia los progenitores del mismo sexo, tenga un carácter adultomórfico y genitalizado, que lo asemeje a una plena elección de objeto amoroso. Más bien lo percibo como un vínculo emocional en el que coexisten el amor y el deseo de identificarse, o sea el amor al Modelo para el propio ser, tal como lo ha planteado Freud en Psicología de las Masas (1980 [1921]), y como lo han retomado Emilce Dio Bleichmar (1998) y Jessica Benjamin (1996). Según considera Benjamin, el amor preedípico no implica una plena elección genitalizada de objeto. Esa autora ha creado el concepto de "amor identificatorio", para referirse a un amor al Modelo, o sea a un sujeto tomado como Ideal sobre el cual el niño o la niña aspiran a construir su ser, asemejándose al mismo. No implica un deseo genitalizado de tener, poseer sexualmente al ser amado, sino que cursa en el ámbito del ser, supone un deseo de ser como el otro. La madre suele ser un modelo para su hija, quien la ama porque desea asemejarse a ella en los aspectos que le resultan admirables.

A esta consideración se agrega la diferenciación psicoanalítica entre la identificación primaria, o sea el vínculo fusional del infante inmaduro con su madre, la identificación melancólica, característica de las relaciones tempranas, fuertemente ambivalentes, y la identificación al rasgo, que es propia del post Edipo, y que hace posible interiorizar características valoradas de los padres, sin que esto modifique la personalidad en su conjunto.

Existe efectivamente un duelo en la construcción normalizada del género, y es el duelo por la omnipotencia infantil y por la aspiración narcisista a la totalidad, que implica el deseo de poseer todos los géneros. Irene Fast (1984) ha denominado al período preedípico como "período sobreinclusivo", y lo caracteriza describiendo que la ansiedad de castración consiste, en esa época del desarrollo, en el temor a perder el sexo que no se tiene. Ese duelo no es objetal sino narcisista, y no tiene, necesariamente, que generar melancolía.

Un error semejante se advierte en la expresión utilizada por Gayle Rubin (1986) al referirse a las niñas pequeñas, a quienes denomina como "la lesbiana preedípica". El amor de las niñas hacia sus madres no está genitalizado de modo pleno, como ocurre en las relaciones lésbicas que se establecen en la adolescencia o en la adultez. Es un apego amoroso, animado por pulsiones aún no organizadas en torno de la genitalidad. En el caso de las mujeres que aman a otras mujeres, ese apego se transforma en deseo a lo largo de sus avatares biográficos, diversos según el caso. El adultomorfismo y la genitalización de ese vínculo temprano, deriva de una formación psicoanalítica que no alcanza el nivel propio de quienes se desempeñan de modo habitual en 
ese campo disciplinario, unida al teoricismo característico de la formación filosófica, y a aspiraciones políticas respetables y compartidas, pero que, sin embargo, no deben dar lugar a retóricas sofísticas.

El recorrido por los mapas disponibles es muy extenso, por lo que estimo pertinente abandonarlo para encarar un eje de análisis y de debate al interior del campo de los estudios psicoanalíticos, incluyendo a aquellos que se relacionan con las teorías feministas. Me refiero a la importancia y el sentido que se atribuye al cuerpo, y el nexo que se establece entre cuerpo, psiquismo y condición social de los sujetos.

\section{Cuerpos, SeXos, GÉneros, Deseos...}

El estatuto social subalterno de las mujeres y su asignación al ámbito familiar que las ha excluido de la participación ciudadana, fue naturalizado durante siglos, mediante una referencia a la diferencia sexual, decodificada como inferioridad con respecto de los varones. Para sustentar esos arreglos de poder, se elaboraron a lo largo de los siglos incontables escritos misóginos, que obraban como caución ideológica de la dominación social masculina. Las académicas feministas elaboraron, a su vez, discursos que buscaban instalar la racionalidad de la paridad social entre mujeres y varones, construyendo un dispositivo alternativo de saberpoder (Foucault, 1980).

Quienes trabajamos dentro del campo del psicoanálisis, elaboramos análisis críticos acerca del discurso freudiano y de otros estudios teóricos y clínicos, desarrollados con esa perspectiva en diferentes regiones y países. También se crearon discursos acerca del carácter patógeno de la condición tradicional de las mujeres, poniendo de manifiesto el modo en que estimulaba conversiones histéricas, limitaciones fóbicas, estados depresivos y trastornos alimentarios, entre otras expresiones de sufrimiento emocional. Hemos buscado establecer una homologación entre subordinación y patología, contrastando esos estados, con otros donde la liberación resultaba saludable. La experiencia ha matizado esas alegaciones iniciales, aunque, si bien el progreso hacia la equidad no ha implicado de modo automático la promoción de estados saludables, es innegable que contribuyó a la expansión del Yo de las mujeres beneficiadas con esos avances, que han logrado mayor autonomía y un mejor desarrollo personal.

No fue difícil combatir un vicio epistemológico, el reduccionismo biologista, que tendía a explicar las tendencias observables en el psiquismo y las conductas que caracterizaban a las mujeres en contraste con los varones, sobre la base de sus características físicas derivadas de la diferenciación sexual. El racismo llegó a su apoteosis durante el régimen nazi, y su derrota, en la Segunda Guerra Mundial, puso de manifiesto la arbitrariedad de sus argumentaciones y el modo en que fueron elaboradas para justificar la aniquilación de diversas poblaciones. Sobre ese descrédito, extendido en Occidente, el sexismo, o sea la discriminación social ejercida sobre la base de las diferencias sexuales, pudo ser impugnado, al punto de que los Organismos Internacionales dedicaron una década y varias conferencias, al avance de la condición femenina en el planeta.

La segunda ola del feminismo desarrolló una rama académica, y las científicas sociales, filósofas y psicoanalistas que nos hemos inscrito en esa corriente de pensamiento, aportamos análisis deconstructivos y relatos alternativos, que lentamente van siendo integrados en los corpus centrales de la sociología, la antropología, la filosofía, el psicoanálisis, la historia, el derecho y las ciencias políticas, entre otros discursos de saber.

De modo que hoy resulta redundante establecer que las personas cuyos cuerpos difieren entre sí por su origen étnico o por su sexo, comparten posibilidades semejantes de racionalidad, y cualidades que les habilitan para la participación social en diversos ámbitos, según sean sus habilidades individuales y la capacitación que hayan adquirido.

Un segundo bastión del pensamiento discriminatorio, tuvo que ser abordado a continuación, y es el referido a la orientación sexual, ya que los sujetos que deseaban a otros de su mismo sexo, fueron blanco del heterosexismo, un prejuicio que consideró a los homosexuales como patológicos, estableciendo una homologación insostenible entre el deseo heterosexual y la salud mental. En nuestro medio, respecto de esta 
cuestión, la Revista Topía, con motivo de su X Aniversario, llevó a cabo una encuesta entre profesionales de la salud mental, que considero oportuno transcribir (Meler, 2000).

\section{"Desde el psicoanálisis, el modo en que se resuelva el complejo de edipo dará como consecuencia la elección de objeto sexual. 1-¿Cómo se fundamentaria, en el campo de la teoría psicoanalitica, si la homosexualidad es una perversión o una sexualidad diferente?}

No acuerdo con la formulación de la pregunta. La alternativa no se plantea entre el diagnóstico de perversión y la categoría de "sexualidad diferente". El interrogante que me resulta más adecuado se refiere a preguntar si la homosexualidad configura una estructura psicopatológica específica, y mi respuesta a esa pregunta es negativa. La elección homosexual de objeto se encuentra en sujetos neuróticos, psicóticos, perversos y caracteriales. Lo mismo sucede con la elección heterosexual. Por supuesto que existen determinantes que permiten comprender ese desenlace subjetivo para cada caso, pero lo que no es posible es una unificación de los homosexuales en una categoría específica.

El deseo homosexual subyace a muchos casos de psicosis, como Freud comprobó en su estudio sobre el caso Schreber. En estos casos, es verosímil vincular la elección homosexual con una retracción de las investiduras libidinales. Los traumas experimentados en las relaciones con los objetos de amor, favorecen dirigir el amor hacia el self, y el semejante del mismo sexo sería entonces, un doble narcisista. Habría que evaluar en qué medida el repudio social hacia la homosexualidad masculina, que comenzó en el Medioevo, contribuye a la génesis de los sentimientos de culpa y a la creación de formaciones delirantes. Es conocido que en muchos delirios paranoides el enfermo escucha voces que lo acusan de homosexual.

El diagnóstico de perversión no se obtiene a partir del tipo de elección de objeto, sino de la estrategia mental que el sujeto despliega en sus vínculos. Si encontramos fijeza, la sujeción de la excitación erótica a un guion inamovible, seducción del partenaire a través de satisfacer su deseo de forma mimética y con el fin de inducirlo a brindar un tipo de satisfacción específica y prefijada, y la aparición de odio destructivo cuando esta condición no se cumple, podemos pensar que estamos ante una personalidad perversa. El semejante es desconocido en su alteridad e instrumentado de forma reificante. A esta altura de la descripción, queda claro que muchos homosexuales no se ajustan a la misma, ya que son capaces de mantener vínculos emocionales afectuosos, establecer lazos de solidaridad y experimentar empatía. En cambio, existen heterosexuales que presentan esta modalidad vincular, p. ej., los que cometen estafas emocionales, los coleccionistas de aventuras eróticas, que suelen ser considerados como exponentes de la virilidad heterosexual convencional.

Otros homosexuales son neuróticos y hoy existe cierto acuerdo acerca de que eso es de lo mejor que le puede ocurrir a un sujeto. Esto sucede debido a que se ha extendido un cierto escepticismo acerca del concepto de salud mental, que en la actualidad es más un ideal normativo que un estado comprobable.

2- ¿Quéfactores considera fundamentales para que un sujeto devenga homosexual?

Me resulta imposible establecer una enumeración exhaustiva. En algunos homosexuales varones he encontrado en sus historias de vida la presencia de una franca seducción por parte de la madre. Esta situación pudo promover que el apego no resignado hacia ella, se retuviera bajo la forma de identificación. Si a esto se agrega el feroz amedrentamiento por parte del padre, que en ocasiones coincide con el primer factor, veremos que el futuro homosexual evita competir por las mujeres permitidas, ya que todas caen bajo el tabú.

Las mujeres son vividas en algunos casos como "contagiosas" y su contacto como potencialmente castrador. La identificación aquí es hipermasculina y la feminidad resulta repudiada. Los partenaires preferidos deben conservar como condición erótica, su aspecto y actitud masculina, ya que si se feminizan, son rechazados.

En otros casos, fue la temprana depresión producto de carencias en el vínculo con la madre, lo que puede considerarse un factor determinante. Una madre percibida como desapegada, rechazante y pseudohipersexual, favoreció una identificación femenina en su hijo. En realidad, se trataba de una identificación materna, y el deseo que estructuraba su proyecto de vida consistía en ser una madre para otros. La práctica de la "fellatio" se encuadraba dentro de ese imaginario.

En otro caso, la muerte prematura de la madre y la depresión de la figura de reemplazo, promovió una identificación melancólica con el objeto perdido, lo que sentó las bases para una identificación femenina en un paciente varón.

3- ¿Cuáles son los recorridos y diferencias en la homosexualidad femenina y masculina?

Son múltiples. Si partimos del carácter asimétrico de la crianza, que hasta ahora ha sido ejercida predominantemente por mujeres en lo que se refiere a los cuidados primarios, vemos que tanto los varones como las niñas aman en primera instancia a sus madres, (con la excepción de las modalidades de crianza postmoderna, donde el padre participa desde el comienzo de la vida). Las mujeres lesbianas continúan entonces con su intenso apego preedípico con respecto de la madre, y no logran instalar lo que Freud denominó el "cambio de objeto", o sea el pasaje hacia preferir al padre, que configura el sustento evolutivo para la actitud heterosexual en la adolescencia y adultez.

En algunos casos la identificación con la madre resulta inaccesible, debido a que ésta es una figura muy idealizada, ya sea por su belleza, prestigio o saber, y a la vez fría y distante. Esta circunstancia puede coincidir con un padre o figura paterna que resulte amedrentador, terrorífico o repugnante, sin que sea posible determinar en qué medida esta percepción deriva del apego de la niña respecto de su madre o de características reales del padre o cuidador masculino. 
Las experiencias de abuso sexual en la infancia, respecto de las cuales las niñas son sus víctimas principales, pueden fomentar una identificación masculina realizada con fines defensivos, algo así como una identificación con el agresor. La condición femenina es experimentada como peligrosa para la integridad del self, y por lo tanto rechazada. La corriente heterosexual queda sí reprimida.

Las circunstancias que favorecen este desenlace subjetivo en las mujeres son diversas, y encontramos mujeres lesbianas hiperfemeninas mientras que otras se masculinizan. Cuando existe una identificación masculina en una mujer, en general resulta de la implementación de una defensa, porque -teniendo en cuenta los sentidos socio-históricos que organizan las prácticas de crianza- la feminidad es la posición primaria para las mujeres mientras que, en el caso de los varones homosexuales, se regresa en ocasiones hacia la identificación primaria, que para los varones, es femenina.

En términos generales, considero que es necesario estudiar caso por caso, y lo que dificulta esa tarea es que está vigente entre nosotros un imaginario colectivo que sanciona la elección homosexual como patológica y al mismo tiempo inmoral. Esta circunstancia favorece que los psicoanalistas sean vulnerables ante la homofobia, con el resultado desdichado de inducir a errores diagnósticos, como el que la pregunta inicial sugiere.

Es útil recordar que existen en todos nosotros corrientes psíquicas hetero y homosexuales y que lo que marca la diferencia es la hegemonía que adquieren una u otra. Esto deriva de la existencia de identificaciones cruzadas con los progenitores del sexo opuesto, identificaciones que a veces contribuyen a la construcción del carácter y que en otros casos, afectan la dirección del deseo. También es cierto que los conceptos de masculinidad y feminidad son pasibles de deconstrucción y que es posible establecer una diferencia entre sujetos del mismo sexo, que no por eso resultan idénticos. La versión de la resolución edípica como el proceso mediante el cual adquirimos la representación de la diferencia sexual y generacional, es aplicada en muchos casos con un criterio estrecho y normalizante. Un sujeto puede haber adquirido una representación de la diferencia y sin embargo, desear lo semejante. Este deseo no se construye forzosamente sobre la fusión regresiva o la indiscriminación, sino que existen diferencias intragénero que sustentan la atracción, y semejanzas que fundan el deseo, no sobre la base de la carencia, sino de la identificación. La elección objetal y la identificación se entremezclan más de lo que el ordenado modelo edípico supone, y muchas veces elegimos objeto sobre el modelo de lo que fuimos o deseamos haber sido, como ya lo demostró Freud en 1914.

Por último, las representaciones sociales hegemónicas y también tendencias imaginarias alternativas, ofrecen los modelos posibles de ser pensados para organizar el magma de nuestras pulsiones parciales en identificaciones y elecciones objetales. No es entonces sobre el sustrato de una pulsión concebida de forma ahistórica, donde encontraremos las claves para comprender la dirección del deseo erótico, sino que debemos articular la dimensión pulsional con el estudio del narcisismo y contextualizar a los sujetos en los regímenes representativos y valorativos de su tiempo y espacio cultural".

Me he permitido transcribir mis respuestas a esta encuesta, porque las considero como un exponente de la sensibilización respecto del enfoque de género, que he realizado al interior de las corporaciones profesionales cuya tarea consiste en la atención de demandas relacionadas con la salud mental de la población. Esta labor apunta a liberar la comprensión y atención del sufrimiento psíquico de la rémora de los prejuicios derivados de la orientación sexual predominante y aceptada, y del sector social aventajado que ha permitido a los operadores del campo de la salud, acceder a su capacitación y desarrollo profesional.

Encuentro de utilidad para comprender el malestar de los sujetos cuyas identidades y deseos divergen de la norma estadística, un concepto aportado por un psiquiatra uruguayo, Marcelo Viñar (2018), cuando propone distinguir las enfermedades del aparato psíquico de un individuo, de las enfermedades del lazo social. Las particularidades no configuran de por sí patologías, pero la discriminación y la exclusión son actitudes patógenas que lesionan la estima de sí de quienes las padecen. Resulta necesario deslindar los aspectos vinculados con sufrimientos de índole biográfica, de su unión, sin embargo inseparable, con los efectos de la mirada reprobadora de los otros, ante la cual todos somos vulnerables.

Las consideraciones etiológicas acerca de los diversos estilos subjetivos y las variadas formas de sufrimiento emocional, no se limitan a quienes presentan estructuras no hegemónicas de la identidad y del deseo. $\mathrm{He}$ elaborado artículos sobre los estados depresivos y sobre las limitaciones agorafóbicas de algunas mujeres tradicionales, el sentido que adquieren las agorafobias masculinas, los riesgos implícitos en las masculinidades hegemónicas y en las mujeres cuyo carácter fue clásicamente tipificado como fálico-narcisista, y los trastornos alimentarios, entre otros desarrollos (Meler, 1996 y 2012). La perspectiva de los estudios de género aporta de modo significativo para una revisión crítica de la psicopatología psicoanalítica, y favorece propuestas alternativas para la atención del malestar emocional. 
Los prejuicios sexistas y heterosexistas se encuentran hoy profundamente cuestionados, aunque el auge actual de los fundamentalismos fascistas en nuestro continente, nos recuerda la necesidad de persistir en una labor de formación de los nuevos profesionales, y en el esclarecimiento de la población en general.

\section{El Destino de los Sistemas de GÉNERos}

Otra cuestión planteada en los comienzos del siglo XXI, afecta la existencia misma de los sistemas de género, que están siendo objeto de ataques radicales que consideran su existencia como un sinónimo de discriminación y opresión. Siempre es difícil establecer una opinión sobre eventos contemporáneos, pero deseo exponer algunas reflexiones provisorias sobre la ignición de las categorías de género, y la posición a la que he arribado de momento, aunque no descarto la posibilidad de que la evolución del cambio social me lleve a modificarla.

Judith Butler (2002) ha expuesto con claridad el modo en que el género y las representaciones acerca del sexo, se vinculan con la reiteración de normas e ideales. Su denuncia acerca del carácter excluyente de esas normativas, y de la constitución simultánea de sujetos ubicados en un centro normalizado y otros sujetos marginalizados en una periferia abyecta, aporta a un proceso de democratización que no atañe solamente a los arreglos legislativos y a las instituciones, sino también a las prácticas educativas y a la asistencia de la salud.

Pero conviene recordar que, si bien las normas y los ideales llevan en sí, de modo implícito, potencialidades segregativas y opresoras, también ejercen un efecto estructurante del intercambio social y de las subjetividades. Los ideales propuestos para el Yo, integran la formación Super Yo, tal como fue teorizada por Freud (1980 [1923]) y, entre otros ejemplos, comandan el trabajo intelectual al que dedicamos tantos esfuerzos. Las normas regulan las relaciones entre las personas y pacifican los conflictos, lo que ha conducido al reconocimiento del valor provisorio de la habilitación del matrimonio para las parejas del mismo sexo. Si bien, como lo expuso Butler (2006), esa reivindicación no puede ser el logro final de una política sexual radical, su logro ha otorgado derechos cuyo disfrute es necesario en el mundo social tal como existe. Muchas personas mejoran sus vidas mediante ese cambio de normativa, y tal vez el tiempo de su existencia se agotaría si se limitaran a esperar una transformación cultural radical.

Las diversas posiciones que los sujetos ocupan en el campo social, habilitan distintas preocupaciones y percepciones acerca de temas de interés común. Es muy comprensible entonces, que quienes han sido marginalizados por las regulaciones heteronormativas, destaquen el daño implícito que ocasionan en la existencia de quienes no se ajustan a esa norma. También se comprende que registren con mayor claridad los aspectos opresivos de la legalidad vigente, y esas visiones se deben incorporar como voces autorizadas en un diálogo epistemológico y político.

Pero conviene también tener presente, que para una proporción de la población que de momento es mayoritaria, la heterosexualidad no es percibida como sinónimo del heterosexismo, sino que constituye un arreglo cultural regulador de un intercambio erótico y amoroso entre mujeres y varones, que les complace. El amor heterosexual ha sido origen de ricas tradiciones relacionadas con el cortejo, la moda y el erotismo, entre otros aspectos de la existencia que concitan un elevado interés psíquico y brindan satisfacción a muchas personas. Para reafirmar esta perspectiva, apelaré a la compañía de Judith Butler, quien en Cuerpos que importan ha expresado: “(...) ese distanciamiento o esa división producida por el entrelazamiento entre los llamados interpelantes y el "yo" que es su sitio, es invasivo, pero también capacitador" (Butler, 2002, p. 181).

Es por eso que, si bien es cierto que el género está en llamas, considero de utilidad rescatar algunos aspectos de las regulaciones de género, en lugar de entregarnos a utopías cuya realización no sólo resulta dificultosa, sino, según considero, poco recomendable.

A medida que la producción teórica que articula desarrollos psicoanalíticos con estudios feministas fue avanzando, la tendencia a describir las subjetividades tradicionales y a criticar los efectos del sistema normativo vigente fue dando lugar al auge del pensamiento utópico, destinado a promover nuevas formas de 
subjetividad, que dieran carnadura a las transformaciones culturales deseadas. En esa tendencia se inscriben las madres trabajadoras de Chodorow (1984), las mujeres que se liberan de los lazos amorosos opresivos, soñadas por Benjamin (1996), los cyborgs de Haraway (1991), la lesbiana propuesta por Wittig (2006) como el sujeto del feminismo, el deseo jubiloso de feminismo descrito por Braidotti (2000) y la mestiza de Gloria Anzaldúa (hooks et al., 2004), entre tantos sujetos utópicos que van cobrando existencia real.

Pero, desde mi punto de vista, en todos los movimientos libertarios anida un germen totalitario, tal como he advertido al asistir a la caída de los socialismos reales. Es de crucial importancia reflexionar acerca de las representaciones acerca de lo deseable que animan nuestras indagaciones.

Se observa en la actualidad una emergencia de modalidades subjetivas que no se inscriben en el binario masculino femenino. La elección homosexual de objeto de deseo es cada vez menos penalizada y más pública, al menos en Occidente. No dispongo de estadísticas, pero mi experiencia clínica me indica que asistimos a un auge del travestismo y el transexualismo (Meler, 2019).

La posibilidad de expresar deseos o modalidades de auto percepción que hasta hace poco cursaban en una situación de clandestinidad, sin duda es políticamente progresista. Pero no creo que la diversidad identitaria y deseante deba dar lugar a una desaparición de las particularidades. Propuestas tales como el Manifiesto Contrasexual de Preciado (2002), una especie de manual que propone generalizar estrategias desnaturalizadoras para des erotizar los genitales y re erotizar diversas partes del cuerpo, con el fin de reemplazarlos en el relacionamiento sexual, me parecen grotescas. La idealización del dominio masculino que la misma autora expresa en Testo Yonqui (Preciado, 2008), donde se explaya acerca de sus deseos de ser el Amo en los intercambios eróticos, me resulta desagradablemente reaccionaria y absolutamente opuesta a lo que entiendo por feminismo (Meler, 2015). El feminismo ha aspirado a obtener una igualdad de derechos, y busca un reconocimiento social similar para sujetos diferentes entre sí. Preciado, en cambio, abjura de toda diferencia, incluidas las diferencias anatómicas, para reivindicar un objetable gusto por la dominación erótica. No aludo a su opción transexual, que forma parte de sus libertades personales, sino a la idealización de lo masculino y el placer que manifiesta en el ejercicio de la violencia erótica y de la subordinación de su partenaire. Al dar ese paso, se ha distanciado del feminismo, eso sí, de modo radical.

Lo sucedido con las tradiciones étnicas en el auge de la globalización puede servir como orientación respecto de las cuestiones de género y evitar extravíos. La puesta en contacto de costumbres, normas y valores muy diferentes entre sí, no condujo a una fusión indiferenciada, sino que activó en muchos casos los regionalismos, donde las tradiciones ancestrales fueron revalorizadas y exhibidas como un atractivo ante los visitantes de otros lugares.

Las diversas identidades, ya sean estables o fluctúen a lo largo del ciclo vital, expresan modos idiosincrásicos de existencia que conllevan valores positivos, y son fuente de goce para quienes se estructuran en esos estilos subjetivos. El hecho de que hayan sido utilizadas a lo largo de la historia para atizar enfrentamientos narcisistas entre Nosotros y Ellos, no debiera conducir a buscar su abolición.

Para continuar con esta argumentación, retornando a Butler, deseo discutir la siguiente aseveración: “(...) nada garantiza que exponer la condición naturalizada de la heterosexualidad baste para subvertirla" (Butler, 2002, p. 325).

¿Por qué se plantea la autora subvertir la heterosexualidad? Lo que debe ser subvertido es el heterosexismo, o sea la discriminación de los sujetos homosexuales, en función de la idealización del vínculo amoroso cuya consumación sexual implica potenciales consecuencias reproductivas. La heterosexualidad es una orientación del deseo, y no requiere otra subversión que no sea aquella que se vincula con la erotización del dominio masculino y la subordinación de las mujeres, que, en efecto, la impregnan profundamente. El hecho de que la historia de la civilización coincide con el dominio masculino, implica, de modo inevitable, que la historia de la sexualidad coincida con la historia de la sexualidad masculina (Irigaray, 1974). La construcción posible de un deseo femenino hacia los varones, que no implique idealización, dependencia emocional, ni subordinación, demanda un trabajo psíquico considerable, que no puede restringirse al ámbito individual, sino que es una 
labor colectiva. Algunas mujeres, según sean sus avatares biográficos, se empeñan en esa empresa, mientras que otras la abandonan para investir con deseo a sus congéneres.

Si abandonamos el terreno estricto de la sexualidad y abordamos las representaciones y valores culturales sobre la feminidad, nuevamente se plantea la necesidad de no tirar el niño con el agua del baño (espero que se me disculpe esta metáfora inoportunamente reproductiva). Posiblemente sea conveniente tirar por la borda la tradicional dependencia obsesiva, frecuente en las mujeres, con respecto del ideal de la belleza, que se relaciona con el imperativo implícito de cotizar lo más alto posible en el mercado sexual. Otro lastre de la feminidad tradicional, se refiere al imperativo indiscriminado del cuidado, que debe quedar obsoleto en un período en que la división sexual del trabajo se va desvaneciendo. Pero no quisiera renunciar al desarrollo de capacidades para la empatía, un logro psíquico que, si bien no es universal entre el colectivo femenino, está más desarrollado tendencialmente entre las mujeres. Esa habilidad es el resultado del confinamiento en el ámbito privado, así como de la asignación a las mujeres de la provisión de los cuidados necesarios para los niños, ancianos y enfermos. Pese a que hoy se evalúe la injusticia de este arreglo, que desconoce el valor económico de las actividades feminizadas, la capacidad empática resultante constituye un valor nada desdeñable para aportar a la convivencia social. Entre otros beneficios, permite modalidades horizontales y cooperativas de liderazgo en el ámbito laboral, y posibilita que las mujeres dispongamos de una facilitación inicial para el ejercicio de la psicoterapia.

En síntesis, deseo hacer explícito que no experimento un antagonismo radical contra las regulaciones de género, sino que sólo me opongo a sus aspectos opresivos. Considero posible desimplicar sus aspectos habilitadores y estructurantes, de los que inducen a la discriminación, y valoro las diferencias de estilos subjetivos como aquello que aporta riqueza e interés al intercambio social.

Tal vez podamos en algún momento agregar una $\mathrm{H}$ que simbolice la heterosexualidad a la sigla GLTTBIQ +1 , para integrar en conjunto, la comunidad humana.

\section{REFERENCIAS BIBLIOGRÁFICAS}

Badinter, E. (1993). XY La identidad masculina. Madrid: Alianza.

Benjamin, J. (1996). Los lazos de amor. Buenos Aires: Paidós.

Benjamin, J. (1997). Sujetos iguales, objetos de amor. Buenos Aires: Paidós.

Braidotti, R. (2000). Sujetos nómades. Buenos Aires: Paidós.

Burin, M. y Meler, I. (2000). Varones. Género y subjetividad masculina. Buenos Aires: Paidós.

Butler, J. (2002). Cuerpos que importan. Buenos Aires: Paidós.

Butler, J. (2006). ¿El parentesco, es siempre heterosexual de antemano?. En Deshacer el género (pp. 149-188). Buenos Aires: Paidós.

Butler, J. (2007). El género en disputa. Feminismo y subversión de la identidad. Barcelona: Paidós Ibérica.

Chodorow, N. (1984). El ejercicio de la maternidad. Barcelona: Gedisa.

Chodorow, N. (1989). Feminism \& Psychoanalytic Theory. New Haven \& London: Yale University Press.

Connell, R.W. (1995). Masculinities. Cambridge: Polity Press.

Dio Bleichmar, E. (1998). La sexualidad femenina. De la niña a la mujer. Buenos Aires: Paidós.

Fausto-Sterling, A. (2006). Cuerpos sexuados. Melusina: Barcelona.

Fast, I. (1984). Aspects of early gender development: Toward a reformulation. Psychoanalytic Psychology, 7, 105-117.

Flax, J. (1995). Psicoanálisis y Feminismo. Pensamientos fragmentarios. Madrid: Cátedra.

Foucault, M. (1980). Historia de la sexualidad. Tomo I: La voluntad de saber. Madrid: Siglo XXI.

Freud, S. (1980 [1908]). La moral sexual cultural y la nerviosidad moderna. En S. Freud, Obras Completas. Tomo XI (pp. 159-181). Buenos Aires: Amorrortu. 
Freud, S. (1980 [1914]). Introducción del Narcisismo. En S. Freud, Obras Completas. Tomo XIV (pp.65-98). Buenos Aires: Amorrortu.

Freud, S. (1980 [1918]). El tabú de la virginidad. En S. Freud, Obras Completas. Tomo XI (pp. 285-203). Buenos Aires: Amorrortu.

Freud, S. (1980 [1921]). Psicología de las masas y análisis del Yo. En S. Freud, Obras Completas. Tomo XVIII (pp. 63-136). Buenos Aires: Amorrortu.

Freud, S. (1980 [1923]). El Yo y el Ello. En S. Freud, Obras Completas Tomo XIX (pp. 161-176) Buenos Aires: Amorrortu.

Freud, S. (1980 [1924]). El problema económico del masoquismo. En S. Freud, Obras Completas. Tomo XIX (pp. 161-176). Buenos Aires: Amorrortu.

Freud, S. (1980 [1933). La femineidad. Nuevas Conferencias de Introducción al Psicoanálisis. En S. Freud, Obras Completas. Tomo XXII (pp.104-125). Buenos Aires: Amorrortu.

Haraway, D. (1991). Ciencia, cyborgs y mujeres. La reinvención de la naturaleza. Madrid: Cátedra.

Hooks, B.; Brah, A.; Sandoval, C.; Anzaldúa, G. (2004). Otras inapropiables. Feminismos desde las fronteras. Madrid: Traficantes de sueños.

Irigaray, L. (1974). Speculum. Espéculo de la otra mujer. Madrid: Saltés.

Kaplan, L. (1994). Perversiones femeninas. Buenos Aires: Paidós.

Kimmel, M. (1994). Masculinity as Homophobia. Fear, Shame and Silence in the Construction of Gender Identity. En H. Brod y M. Kaufman (eds). Theorizing Masculinities (pp. 119-141). Thousand Oaks: Sage Publications.

Meler, I. (1996). Psicoanálisis y Género. Notas para una psicopatología. En M. Burin y E. Dio Bleichmar (comps.), Género, Psicoanálisis, Subjetividad (pp. 241-266). Buenos Aires: Paidós.

Meler, I. (2000). Homosexualidad: ¿perversión o sexualidad diferente? Revista Topia, Revista de Psicoanálisis, Sociedad y Cultura, X(30), 4-7.

Meler, I. (2012). Las relaciones de género. Su impacto en la salud mental de mujeres y varones. En C. Hazaki (comp.), La crisis del patriarcado (pp. 23-46). Buenos Aires: Topía.

Meler, I. (2013). Recomenzar. Amor y poder después del divorcio. Buenos Aires: Paidós.

Meler, I. (2015). Las huellas eróticas de la subordinación. En C. Barzani (comp.), Actualidad de Erotismo y Pornografia (pp. 39-61). Buenos Aires: Topía.

Meler, I. (2019). Mesa Redonda "Sexualidades en la clínica psicoanalítica hoy". Revista de Psicoanálisis de la Asociación Psicoanalítica Argentina, 76(1), 137-160.

Preciado, B. (2002). Manifiesto Contrasexual. Madrid: Ópera Prima.

Preciado, B. (2008). Testo Yonqui. Madrid: Espasa Calpe.

Rubin, G. (1986). El tráfico de mujeres. Notas sobre "la economía política del sexo". Revista Nueva Antropología, $\operatorname{VIII}(030), 95-145$.

Stuart Mill, J. (2010 [1869]). El sometimiento de la mujer. Madrid: Alianza.

Viñar, M. (2018). Experiencias psicoanaliticas en la realidad sociocultural. Buenos Aires: Noveduc.

Viveros Vigoya, M. (2002). De quebrados y cumplidores. Bogotá: Universidad Nacional de Colombia, Fundación Ford, Profamilia de Colombia.

Wittig, M. (2006). El pensamiento heterosexual y otros ensayos. Barcelona: Egales. 